\title{
EL BIEN Y EL MAL EN LA CELESTINA
}

Luis Lorenzo-Rivero

Nada envejece tanto como la crítica literaria, ya que con el tiempo se descubren nuevas facetas; y además la interpretación cambia con la mentalidad de la época. Sobre $L a$ Celestina hasta ahora han surgido muchas opiniones, partiendo de Cervantes que la calificó de: "Libro, en mi opinión, divino [...]." Indudablemente es una obra extraordinaria en todo, pasión, motivación fatal, creación de personajes y demás. La crítica moderna se viene centrando primordialmente en torno a la unidad y diversidad de autores, al género literario y otros aspectos por el estilo. Mi propósito es mencionar una faceta distinta por su consideración y significado, la de que La Celestina tiene como objetivo principal corregir el vicio y exaltar la virtud. Ciertamente contiene ideas de la doctrina cristiana de la Edad Media, tales como la del desengaño del mundo que atraviesa la literatura española, penetrándola de estoicismo. Consecuentemente también está presente en ella la negación de la vida que se desarrolla en este mundo, y la idea de fugacidad expresada con la imagen del rio indicador de la transitoriedad. Si se considera el método utilizado por Rojas para condenar el mal y exhortar al bien, pudiera parecer que intenta lo contrario. Por esto debió ser que, a la frase mencionada, Cervantes añadió: "si encubriera más lo humano." No obstante esta forma de contraste, presentando lo reprochable a fin de que el lector recapacite y vea mejor la excelsitud del bien, no es única en la antigüedad. Un buen ejemplo que le sirve de precedente es el Libro de buen amor, en el que el Arcipreste nos dice haberlo escrito con fin didáctico moralizador, y expone a continuación desnuda y poéticamente las lacras humanas de la época.

El propósito didáctico de La Celestina ya aparece expresado en la carta de "El autor a un amigo suyo", cuando ensalza las inusitadas cualidades de la obra: "Vi, no solo ser dulce en su principal historia [...] pero aun de algunas sus particularidades salían deleytables fontezicas de filosofía, de otros agradables donayres, de otros auisos y consejos contra lisonjeros [y] malos seruientes, y falsas mugeres hechiceras."1 Idea en la que vuelve a insistir en los versos acrósticos: pero ahora especifica que estos avisos son para los amantes: "Estos amantes les pornan temor/ A fiar de alcahueta ni falso serviente." 2 Es sólo en unos versos más adelante donde dice explicitamente que pretende descartar el mal e inculcar el bien, la pasión amorosa e implantando en su lugar la virtud: "Amonesta a los que aman que sirvan/a Dios y dexen las malas cogitaciones/y vicios del amor."

La lujuria y la avaricia son los pecados capitales predominantes en la obra, los cuales a su vez engendran otros y causan la destrucción de aquellos en quienes radican. Rojas lo dice por boca de Pármeno en su respuesta a Celestina, cuando ésta trata de atraerlo a su causa y de Sempronio, prometiéndole la posesión de Areusa: 
PAR. - ¡O Celestina! Oydo he a mis mayores que un ejemplo de luxuria o auaricia
mucho mal haze; [...] Y puesto que yo a lo que dizes me incline, solo yo
querria saberlo; porque a lo menos por el exemplo fuesse oculto el peccado. Y si
hombre vencido del deleyte va contra la virtud, no se atreua a la honestad. ${ }^{4}$

La tesis del autor es que la pasión domina al ser humano por completo, hasta llevarlo a la perdición. Valera, al considerar los amores de Calisto y Melibea, no podía comprender la incongruencia de que no habiendo obstáculos no se casasen. Le parecía que Rojas había hecho abstracción de todo menos del amor para resaltarlo y glorificarlo, pero el crítico no se dio cuenta que lo que domina a esta pareja es la pasión irracional. En el argumento ya se afirma que a "amargo y desastrado fin" van a parar los personajes principales abatidos por las más violentas pasiones, volviéndose a insistir en ello en el texto de la obra como ocurre en el acto VIII por medio de Sempronio:

SEM. - ¿Que es esto, desuariado? Reyrme querria sino que no puedo. ¿ Ya todos amamos? El mundo se va a perder. Calisto a Melibea, yo a Elicia, tu de embidia has buscado con quien perder esse poco de seso que tienes. ${ }^{5}$

Calisto y Melibea de no ser porque se llegan a ver esclavos de la lujuria, principalmente él, por lo demás son un cúmulo de bondades. Aquí es donde se encuentra el principio de la lucha entre estos dos mundos diametralmente opuestos, el del bien y el del mal, en que se desarrolla la obra. La acción comienza con Calisto en el huerto de la doncella deslumbrado por su hermosura, que le cautiva de amor. Hasta este punto su sentimiento es verdadero y sincero, es de gozo en la contemplación de la belleza; pero se está saliendo de quicio al darse cuenta de la limitación de este placer y de la impureza que lleva su pensamiento:

CAL. - [...] Por cierto, los gloriosos santos, que se deleytan en la visión diuina, no gozan mas que yo agora en el acatamiento tuyo. Mas $j^{0}$ triste! que en esto deferimos: que ellos puramente se glorifican sin temor de caer de tal bienauen. turança, y yo, misto, me alegro con recelo del esquiuo tormento, que tu ausencia me ha de causar. ${ }^{6}$

Al oir esas palabras Melibea percibe el proceso de transformación del espíritu de Calisto, sabe que su amor se está convirtiendo en pasión. Consecuentemente lo rechaza sólo porque está motivado por el apetito desordenado, no por ser amor, lo cual desea ardientemente, si bien no le está permitido expresarlo debido a su calidad de mujer en aquella sociedad:

MEL. - [ ... $]$ Y el intento de tus palabras ha seydo [como] de ingenio de tal hombre como tu, auer de salir para se perder en la virtud de tal muger como yo. jVete, vete de ay, torpe! Que no puede mi paciencia tolerar que aya subido en coraçon humano comigo el illicito amor comunicar su deleyte. ${ }^{7}$

Inmediatamente después de abandonar la presencia de Melibea, Calisto da muestras de aturdimiento proveniente de su pasión, manifestándose uraño con Sempronio apenas entra en casa, hasta tal punto que su actitud crea en el criado temores de que cometa suicidio. El ardor le crece con rapidez y a él se entrega ciegamente, considerando a la amada su dios y señor. Muy poco después confiesa a este mismo sirviente que lo devora la excitación en la que se deleita en su dolor y congoja: 
CAL. - [.. . Haz de manera que en solo verte ella a tí, juzgue la pena que a mi queda, y fuego que me atormente. [...] Tu como hombre libre de tal passion, hablarle has a rienda suelta. 8

Incluso llega a caer en una especie de delirio frenético, de desvarío y locura, obseso en la posesión del cuerpo de Melibea. Tal le ocurre en el momento que Celestina le trae el cordón que la joven le envía para la cura de su dolor de muelas. Entonces él se dirige a la cinta como si fuese la amada misma, envidiando en ella que pudiese ceñir aquellas partes del cuerpo de la mujer que desea poseer y ni siquiera le es permitido contemplar:

CAL. - $\mathrm{i}$ nueuo huesped! $\textrm{O}$ bienauenturado cordon, que tanto poder y merecimiento touiste de ceñir aquel cuerpo, que yo no soy digno de servir! $¡ \mathrm{O}$ ñudos de mi passion, vosotros enlazastes mis desseos![ ...] ¡O mezquino de mi! Que assaz bien me fuera del cielo otorgado, que de mis braços fueras hecho y texido, y no de seda como eres, porque ellos gozaran cada dia de rodear y ceñir, con deuida reuerencia, aquellos miembros que tu, sin sentir mi gozar de la gloria, siempre tienes abraçados. O que secretos auras visto de aquella excellente ymagen. ${ }^{9}$

Así lo juzgan también aquellos que le rodean, como su criado Pármeno cuando le oye en la primera entrevista con Melibea querer romper las puertas de su casa para gozarla: " ¡Desuariar, Calisto, desuariar!"1 o Este encendimiento se apodera también y con igual fuerza de la doncella, a la que obliga a saltar todas las barreras de la razón así como las sociales:

MEL: - ¡O lastimada de mi! ¡O mal proueyda donzella! ¿Y no me fuera mejor conceder su petición y demanda ayer a Celestina, quando de parte de aquel señor, cuya vista me catiuo, me fue rogado, y contentarle a el y sanar a mi, que no venir? iQuanta mas ventaja touiera mi prometimiento rogado que mi offrecimiento forçoso! ${ }^{11}$

Como en el caso de Calisto, es aquí su criada, Lucrecia, la que nos advierte que su ama ha perdido la razón dominada por la pasión de la lujuria: "El seso tiene perdido mi señora. Gran mal ay." 12 He ahí el drama íntimo de estos seres apasionados, se debaten en la contradicción interna de, a pesar de conocer el camino del bien, verse arrastrados inevitablemente al pecado.

Contra estas inclinaciones bajas de la pasión el hombre dispone de la razón, de la prudencia y otras virtudes que lo dignifican. El autor de La Celestina pretende evidenciar que la parte espiritual es más sublime y merece más atención que la material, si bien comúnmente resulta más agradable seguir los instintos de la carne que los consejos del alma. El desacuerdo entre las fuerzas del instinto y la virtud constituye una lucha entre el "bien" y el "mal", que Rojas representa literariamente sirviéndose de caracteres que unas veces encarnan un valor abstracto y otras un ser humano con sus vicios y virtudes. Tal se puede considerar el caso de Sempronio y Pármeno en relación con Calisto, que unas veces encarnan la razón y prudencia de su amo y otras son sus servidores falsos, asociándose con Celestina para satisfacer su propia lujuria y codicia, yendo deliveradamente contra el bien de su amo. Sempronio desde muy pronto en el acto l aparece como un sirviente sumiso, humano de clase humilde. Esto se observa fácilmente en la escena en que Calisto llega a casa después de encontrarse con Melibea en su huerto, se encierra exasperado por la pasión, el criado duda si entrar a consolarlo y en ese momento el amo lo llama: 

CAL. - ¡ Sempronio!
SEM. $-i$ Señor?
CAL. - Dame aca el laud.
SEM. - Señor, veslo aqui.

El diálogo continúa apuntando hacia el aspecto de encarnación de la razón que luego representará Sempronio, pero todavía es el criado humilde y temeroso:

CAL. - Mayor es mi fuego, y menor la piedad de quien agora digo.

SEM. - No me engaño yo, que loco esta este mi amo.

CAL. $-i$ Que estas murmurando, Sempronio?

SEM. - No digo nada. ${ }^{13}$

La otra faceta del personaje Sempronio, la de simbolizar la razón de Calisto, surge inmediatamente en esta escena del acto I. El señor se encuentra turbado en su interior por el instinto carnal que le arrasta fuertemente, y el criado trata de enfriarlo hablándole en una forma confianzuda y protectora. Es la razón que trata de imponerse sobre la pasión, el bien que procura triunfar sobre el mal, aunque en realidad éste es el que saldrá triunfante:

CAL. - ¿Que te parece de mi mal?

SEM. - Que amas a Melibea.

CAL. - ¿Y no otra cosa?

SEM. - Harto mal es tener la voluntad en un solo lugar catiua.

CAL. - Poco sabes de firmeza.

SEM. - La perseuerancia en el mal no es constancia, mas dureza o pertinacia la llaman en mi tierra. Vosotros los filosofos de Cupido llamaldā como quisierdes. ${ }^{14}$

El instinto se rebela y no quiere someterse a la razón, que insiste en sus esfuerzos para calmarlo y traer al hombre a la realidad, presentándole casos desastrosos del pasado. Pero la pasión renueva sus ataques con más fuerza sin darse nunca por vencida:

CAL. - ¿Vees? Mientras mas me dizes y mas inconuenientes me pones, mas la quiero. No se que es.

SEM. - No es este juyzio para moços, segun veo, que no se saben a razon someter, no se saben administrar. ${ }^{15}$

Los consejos continúan, sin que el apetito pasional ceda, es como potro desbocado que atropella la razón y sensatez, sin darse cuenta de su engaño hasta después de satisfecho cuando es demasiado tarde:

SEM. - Possible es. Y $Y$ aun que la [aborrezcas] quanto agora la amas podrá ser, alcançandola y viendola con otros ojos, libres del engaño en que agora estas.

CAL. - ¿Con que ojos?

SEM. - Con ojos claros.

CAL. - Y agora, ¿con que la veo?

SEM. - Con ojos de alinde, con que lo poco parece mucho y lo pequeño grande. ${ }_{16}$ porque no te desesperes, yo quiero tomar esta empresa de cumplir tu deseo. 
La razón ya está vencida, ahora la pasión se encuentra libre de este obstáculo para lograr su propósito. Entonces Sempronio pasa de símbolo a su condición ordinária de sirviente interesado en su lucro a expensas del amo. La promesa de cumplirle su deseo es la decisión de traer a Celestina y, en unión con ella, fomentar las esperanzas de su pasión para así fácilmente arruinarlo.

El otro criado, Pármeno, igualmente se caracteriza por esa dualidad: la de símbolo de virtud de Calisto y la de servidor. En la función primera, que es más persistente y variada que la de Sempronio, personifica principalmente la prudencia, persistiendo en hacerle distinguir lo bueno de lo malo, aconsejándole a obrar con buen juicio y no caer en las garras de la pasión: "Oyeme, y el affecto no te ensorde, ni la esperança del deleyte te ciegue. Tiemplate y no te apresures; que muchos con codicia de dar en el fiel yerran el blanco." ${ }^{17}$ La carne no presta atención a estos y otros semejantes avisos del espíritu, por el contrario, cuanto más le quiere hacer ver la ruina a que le conduce la pasión más fuerza cobra ésta. Este triunfo del "mal" sobre el "bien" es lo que el autor desea corregir en la sociedad de su tiempo:

PAR. - Señor, porque perderse el otro día el nebli fue causa de tu entrada en la huerta de Melibea a le buscar; la entrada, [causa] de la ver y hablar; la habla engendro amor; el amor pario pena; la pena causara perder tu cuerpo y [el] alma y hazienda. Y lo que mas dello siento es venir a manos de aquella trotaconuentos, despues de tres vezes emplumada.

CAL. - Assi, Parmeno, di mas desso, que me agrada. Pues mejor me paresce quanto mas la desalabas. ${ }^{18}$

La prudencia le advierte por boca del criado que es mucho mejor y honesto que abandone la loca pasión y ame a Melibea lícitamente, proponiéndola a ella directamente sin intervención de tercera pues les es alcanzable. Sus deseos y los medios que utiliza para conseguirlos son ilícitos, sólo le conducirán a su destrucción:

\footnotetext{
PAR. - Digo, señor, que yrian mejor empleadas tus franquezas en presentes y servicios a Melibea, que no dar dineros a aquella que yo me conozco y, lo peor es, hazerte su catiuo. 19
}

He ahi la explicación a la incongruencia que encontraba Valera en el amor entre Calisto y Melibea, ya que no había ningún tipo de obstáculo social, religioso, etc. que les impidiera casarse. El gran inconveniente era la pasión de la lujuria que dominaba ese amor. Este vicio destruye al que lo posee, principalmente si es joven sin experiencia, y a los que le rodean, como dice la propia alcahueta Celestina:
CEL. - Mayormente estos novicios [amantes], que contra qualquier señuelo buelan sin deliberación, sin pensar el daño, que el ceuo de su desseo trae mexclado en su exercicio y negociacion, para sus personas y sirvientes. ${ }^{20}$

El tipo de los criados de Calisto, en su papel de tales, es un tipo rufianesco, especialmente Sempronio. Este es el primero que, dándose perfecta cuenta del estado de pasión de su amo, determina utilizar esa oportunidad en su propio interés. Bajo el impulso del pernicioso vicio de la codicia, y porque el solo no se basta, busca a Celestina como ayuda y socio en su empresa: 
Assi es [...] Calisto arde en amores de Melibea. De ti y de mi tiene necessidad. Pues juntos nos ha menester, juntos nos aprouechemos; que conoscar el tiempo y usar el hombre de la oportunidad haze los hombres prosperos. ${ }^{21}$

Está tan dominado por la avaricia que quiere darse la mayor prisa posible a lucrarse de su amo, por temor de que su fiebre pasional se enfrie con el tiempo, recobre su sentido y ya no puedan conseguir riquezas materiales:

Pues assi sera este amor de mi amo: - dice Sempronio a Celestina - quanto mas fuere andando, tanto mas diminuyendo. [...] Procuremos prouecho mientra pendiere su contienda; y si a pie enxuto le pudieremos remediar, lo mejor mejor es; y si no, poco a poco le soldaremos el reproche o menosprecio de Melibea contra el. ${ }^{22}$

Pármeno se mantiene fiel durante más tiempo, luchando contra la pasión de Calisto y otros vicios y males contenidos en las personas de Sempronio y Celestina. Pero por fin también él pasa a la realidad de criado infiel, convertiéndose en un servidor más vil que Sempronio. Su perversión es obra de Celestina, que sabe que para triunfar totalmente en su maldad tiene que tener de su parte a ambos criados. El muchacho al principio duda de la conveniencia de pasarse al partido de la alcahueta, abandonando así a su amo:

Celestina, todo tremo en oyrte. No es que haga, perplexo estoy. Por una parte, tengote por madre, por otra, a Calisto por amo. Riqueza desseo; [pero] quien torpemente sube a lo alto, mas ayna cae que subio. No querria bienes mal ganados. ${ }^{23}$

No obstante, dominado por la codicia y la envidia, deseoso de medrar, sucumbe en el mal y se asocia con Celestina y Sempronio, víctima del engaño del mundo:

¡ O desdichado de mi! Por ser leal padezco mal. Otros se ganan por malos, yo me pierdo por bueno. ¡ El mundo es tal! Quierome yr al hilo de la gente, pues a los traydores llaman discretos, [y] a fieles necios. ${ }^{24}$

La codicia se manifesta de un modo más fuerte en este criado Pármeno que en Sempronio, pues su asociación con la vieja no es sincera, posponiéndola siempre a su proprio interés: " $i$ Assi, assi! - responde a su amo que le manda llamar al sastre para que corte el manto y saya a Celestina - A la vieja todo, porque venga cargada de mentiras como abeja, y a mi que me arrastren." 25 Esta tremenda avaricia suya le hace impaciente, mientras Sempronio que no es $\tan$ avariento lo calma y le aconseja espera, pues ya les llegará a ellos el momento de lucrarse débidamente.

PAR. - Bien sufriré yo que pida y pele; pero no todo para su prouecho.

SEM. - No tiene otra tacha sino ser cobdiciosa; pero dexala barde sus paredes, que despues bardara las nuestras o en mal punto nos conocio. ${ }^{26}$

Otros pecados capitales y vicios ataca Rojas en su obra para hacer resaltar más las virtudes que se le oponen, y esto es evidente en la acusación de Calisto a Pármeno:

Fingiendote fiel, eres un terron de lisonja, bote de malicias, el mismo meson y aposentamiento de la embidia. Que por disfamar la vieja a tuerto o a derecho, pones en mis amores desconfiança, sabiendo que esta mi pena y flutuoso dolor no se rige por razón, no quiere auisos, carece de consejo. 27 
El mayor de estos males, causa de la destrucción de aquellos en quienes reina y origen de todos los otros, es la lujuria, al que le sigue la codicia. En torno a estas dos calamidades humanas y dependiendo de ellas, se hallan las demás. En el colapso de este mundo de inmundicia, las primeras víctimas que caen son los avarientos, los cuales se destruyen unos a otros. Ahí está, para confirmarlo, el ejemplo de Sempronio y Pármeno, que dan muerte a la vieja Celestina y, a su vez, son eliminados al punto por la justicia, el bien. La pareja de enamorados también perece castastróficamente víctima de sus pasiones, pero al final. Lo que Rojas condena en ellos y, a través de ellos, en la sociedad de su época es la pasión, no el amor per se, como cree Luis Rubio, entre otros. El amor no es mal para Rojas, la lujuria sí y horrendo muy corriente entre aquella juventud de España.

\section{Department of Languages \\ University of Utah \\ Salt Lake City, USA}

\section{NOTAS}

${ }^{1}$ La Celestina, edición crítica por M. Criado de Val y G. D. Trotter, Madrid: C.S.I.C., 1964, p. 4.

2 Ibid., p. 10.

3 Idem.

${ }^{4}$ Ibid., p. 56.

5 Ibid., p. 154.

6 Ibid., p. 23.

7 Ibid., p. 24.

8 Ibid., p. 63.

9 Ibid., pp. 122, 123 y 124.

10 Ibid., p. 213.

11 Ibid., p. 182.

12 Ibid., p. 187.

13

Ibid., pp. 26-27.

Ibid., pp. 28-29.

15 Ibid., p. 32.

16 Ibid., p. 35.

17

Ibid., p. 46. 
18 Ibid., p. 66.

${ }^{19}$ Ibid., p. 65.

${ }^{20}$ Ibid., p. 70.

21 Ibid., p. 39.

22 Ibid., pp. 71-72.

23 Ibid., p. 54.

24 Ibid., p. 68.

25 Ibid., p. 121.

26 Ibid., p. 113.

27 Ibid., p. 66. 